\title{
A Comprehensive Knowledge Pedigree on Environmental Transparency
}

\author{
Rui Yang ${ }^{1}$, Ziwei Duan², Mengjin Du ${ }^{1}$, Xin Miao ${ }^{1 *}$ \\ ${ }^{1}$ School of Management, Harbin Institute of Technology, Harbin 150001, China \\ ${ }^{2}$ School of Humanities, Social Sciences \& Law, Harbin Institute of Technology, Harbin 15001, China
}

Received: 10 February 2020

Accepted: 2 June 2020

\begin{abstract}
Environmental transparency issue has drawn increasing concern, and the related research has shown explosive growth. A comprehensive knowledge pedigree of environmental transparency can help understand the spatial and temporal distribution of themes, research categories, cutting-edge research topics and development trends of environmental transparency research, providing research opportunities for the future. Based on the: Social Science Citation Index database in the Web of Science, this article retrieves 930 papers with the theme of "environment transparency" in all years, and analyzes the its knowledge system via the software of CiteSpace. Keywords co-occurrence analysis function is applied to identify keywords and their occurrence frequency in environmental transparency literature, and a keyword co-occurrence network was generated on the basis of high-frequency keywords to explore the knowledge base in the field of environmental transparency research. Then, through co-citation analysis and cluster analysis, the high-frequency co-citation literature and four hot research paradigms of environmental transparency are identified to present the knowledge domain of its research. Next, the paper uses the time zone and strong citation burst analysis to detect the situation where the reference volume changed significantly during a certain period of time, in order to discover the decline or rise of a key keyword in the beginning, development, and cutting-edge period in environmental transparency research field, which contributes to unearth the knowledge evolution path of environmental transparency and reveal how researches related to environmental transparency have evolved over time. Finally, according to the knowledge base, knowledge domain, and knowledge evolution, a visual knowledge graph is constructed to provide a comprehensive review of existing research in the field of environmental transparency.
\end{abstract}

Keywords: environmental transparency, CiteSpace, knowledge pedigree, comprehensive review

*e-mail:miaoxin@hit.edu.cn 


\section{Introduction}

With the increasingly prominent problems of resource consumption and serious environmental pollution, local governments increase environmental transparency (ET) through environmental information disclosure to strengthen the supervision and improve environmental policies for reducing pollution [1]. Accordingly, ET has gradually become one of the important indicators for measuring environmental responsibility of governments and corporations [2]. In order to systematically evaluate the implementation of relevant regulations by local governments, Institute of Public and Environmental Affairs and The Natural Resources Defense Council jointly developed the Pollutant Information Transparency Index (PITI) in 2009, and have evaluated the transparency of pollution source regulatory information in 113 cities across the country for 9 consecutive years, it is considered a good measurement tool to reflect the transparency of local governments [3]. Peng et al. [4] found that the ET of local governments can mitigate the relationship between local governments and local citizens when local air quality deteriorates. The requirement of ET can also promote corporations to re-understand their environmental responsibilities, create a competitive atmosphere, strengthen public supervision, and improve the efficiency of government law enforcement, which will effectively promote energy conservation and even economic transformation [5]. Additionally, Simões \& Marques [6] believed that the sunshine regulation required from ET can obviously improve the quality of service regulation in the performance of urban waste services and enable to encourage the enhancement of efficiency and innovation among waste utilities. Given the profound roles of ET in both academics and practices, it is of great significance to explore the knowledge pedigree of ET to better find the internal connection between existing research topics and contribute to advancing the current knowledge of ET.

While, with increasing attention to ET, more and more scholars in different fields have introduced various research methods and research tools into the research field of ET, making the study of ET have interdisciplinary characteristics (e.g. [7, 8]). As a result, the research topics related with ET are very rich, and research hotspots emerge frequently [9]. As the knowledge development is a dynamic process [10], it may difficult for readers to grasp the research focus and track its developing trends from a large number of sources by only depending on non-visualization technology [11]. It is necessary to use scientific and visual metrology software [12] to provide a knowledge pedigree to sketch the research field to help people meet the challenges [13]. Hence, the paper tries to systematically review the existing research with visualization techniques to clarify the current research status and the development trend in this field, thus to provide directions for future research and practices.
In traditional systematic reviews, scholars often used NoteExpress, Bibexcel and Ucinet as the main mining and visualization technologies to construct a keyword knowledge map to explore the current research status of a certain field, by analyzing the cooccurrence relationship between keywords. After decades of development, this type of research has rich theoretical and practical experience (e.g. [12]). With the continuous development of scientific metrology tools, much new software such as VOSviewer, CoPalRed, and CiteSpace have outperformed traditional bibliometric tools and gradually become better choices for literature review. CiteSpace is a great visualization software for existing research literature metrology research. It is an exceedingly useful analysis tool, as it has more comprehensive functions and is convenient to use, compared with other software [10]. Firstly, it is diverse, time-sharing as well as dynamic for visualizing citations with the development of scientometrics, data and information visualization techniques. It is designed to analyze the basics contained in scientific literature [14]. Moreover, it supports literature co-citation analysis and keywords co-occurrence analysis, which can help researchers perform quantitative and objective analysis of related fields and reveal the quantitative relationship between various different studies [15]. Then, through the combination of quantification and visualization, scholars can find hidden connections and trends in related literature. Specifically, it can help people understand the spatial and temporal distribution of research, current research status, cutting-edge research and development trends of research [10] Additionally, it should also be emphasized that it cannot only show the overall situation of a research field, but also highlight some important literature in the development of this field [16]. In view of its comprehensive bibliometric capabilities and high reliability, it has been widely used in recent two years [17]. In the view of the strong and comprehensive functions of CiteSpace software, the study thus applies it as a bibliometric tool to facilitate a comprehensive review of related research in the field of ET, to more systematically build a knowledge pedigree of ET.

By referring to the work of Shi et al. [10], this paper constructs an ET knowledge graph from three aspects: ET knowledge base, ET knowledge domain, and ET knowledge evolution, in order to find the hot issues in the current research, and to guide the research in the field of ET in the future. Specifically, this article used the keyword co-occurrence analysis to find high-frequency keywords in the ET field to build an ET knowledge base. High-frequency keywords are the basis for a series of research issues such as the spatial and temporal distribution of research, current research status, cuttingedge research, and future development directions (e.g. [18]). Then, this article employed literature co-citation analysis and cluster analysis of CiteSpace to find out the specific distribution of the current research and research paradigms of ET to build an ET knowledge domain. 
It is a visual description of the current research status, and elaborates the key research categories that have been paid attention to. Exploring the ET knowledge domain can help to understand the research experience and results of ET, and thus provide reliable support for ET knowledge evolution. Finally, according to the results of ET knowledge base and ET knowledge domain, this article used the time zone map and the strong citation burst functions of CiteSpace software to construct ET knowledge evolution. The key to this step is to identify emerging research terms at each stage. Because the visual ET knowledge evolution can enable researchers to clearly understand the evolution process of ET research hotspots, helping to grasp context and provide support for understanding the research frontier. Accordingly, the ET knowledge graph designed by combining ET knowledge base, ET knowledge domain, and ET knowledge evolution is the ET knowledge system. It is a summary of the findings in this review. The combination of modeling with visualization can not only help readers to understand the research results but also enable to understand systematical knowledge and enrich the knowledge system in the ET field, providing theoretical support and practical guidance for future research.

To realize the set targets, the paper is organized as follows. It first conducts a conceptual and theoretical review, covering the frequently mentioned concepts and theories of ET, to lay the groundwork for the comprehensive review. Then, the materials and main methods in the work is introduced in detail. Furthermore, bibliometrics analysis is provided. Discussion covers elaboration on ET knowledge base, ET knowledge domain, and ET knowledge evolution. A visual knowledge graph on ET is constructed as a summary of the paper's findings, which enables to present the major concerns and future research directions of ET in a holistic manner. Finally, the paper draws conclusions and provides some implications for future study.

\section{Conceptual and Theoretical Review}

The following summarizes the relevant ET concepts in the existing literature. Transparency of information is defined as the sharing of useful information, which is operated by relevant institutions, encourage citizen participation, and open to public supervision [19]. In the 1990s, RIO Declaration on Environment and Development and Aarhus Convention of the 1990s have emphasized the importance of public access to environmental information [20, 21]. Nowadays, more and more countries are institutionalizing ET into environmental standards or business regulations [22], enabling stakeholders to intentionally or unintentionally access environmental information through different channels in daily lives [4], so as to potentially develop their good environmental protection habits and establish environmental awareness. In the long run, ET will penetrate into different market sectors and institutions, such as corporations, news media and non-governmental organizations [22]. This will not only help to strengthen the environmental awareness of corporations and make them consciously reduce environmental pollution, but also make the news media and non-governmental organizations more effective in strengthening supervision. In addition, Tian et al. [3] believed that ET is a mechanism that can promote social awareness of perceiving pollution. ET can also create opportunities for stakeholders to enable them to better obtain objective information related to environmental policies, budgets, environmental quality conditions and corporate environmental performance, thereby helping to increase their environmental awareness [4]. It has been applied as a policy tool that breaks the impasse in environmental governance caused by top-down political system [19].

However, some scholars have pointed out that ET requires extensive data collection and monitoring for environmental governance, which is often impossible for less developed countries, thus exacerbating the power gap [23]. Moreover, the requirements for ET usually require more national surveillance and regulation. Simões \& Marques [6] stated that the sunshine regulation can positively influence the quality of service improvement and contribute to the decreasing of overinvestment in utilities. Based on legitimacy theory, corporations with poor environmental performance are facing more political pressure [24]. In order to enhance their impression management, they will voluntarily disclose more environmental information to make their behavior "legal" [25]. According to political economy theory, those corporations with poor environmental performance use environmental information disclosure as a way to protect their own interests and maintain and legalize their social relationships [26, 27]. Corporations use the requirements of ET as a "masking tool" rather than a "communication tool" [28]. In view of such evidence and requirements for environmental disclosure, ET will cause information overload, and the accuracy of all disclosed information is difficult to verify, and may even lead to paralysis of decisionmaking. Thereby, ET works only if the quality of the information is guaranteed [23].

Through the above analysis, it can be found that most of ET research is related to environmental knowledge such as environmental information disclosure system. At present, the research on ET has involved many disciplines such as politics, environmental studies, economics, marketing, organization management, etc. (e.g. [29, 30]). As mentioned above, legitimacy theory and political economy theory are often used in the study of ET. In addition, theories such as the triple bottom line principle, organization theory, and signal transmission theory are also widely used in the study of ET (e.g. [31, 32]). In recent years, more and more studies on ET have shown that ET is of great significance to the 
development of the society today [33]. Thereby, both the academic and the practice should better understand the changes and issues in the implementation of ET.

\section{Materials and Methods}

It is notable that this work uses the PRISMA method [34] to select articles on the topic of ET in the Web of Science (WoS) core database. The method is divided into four steps: identification, screening, eligibility, and included, which can ensure the quality of the comprehensive study. This process will be discussed in detail below.

\section{Material Sources and Processing}

Systematic reviews should be on the basis of describing the principles, assumptions and planning methods of the evaluation. As a result, identifying research questions is the first step in selecting articles [34]. The main purpose of this work is to build a complete ET knowledge system. Namely, it is to present the efforts and results of scholars in the ET field, and to provide the latest progress in the research literature of this field, and to discover opportunities to promote the development in future. To achieve these targets, this paper will discuss the process of selecting publications in the following.

Firstly, this article selected the Social Science Citation Index (SSCI) database in the WoS as the data resource. First, WoS covers broadly research areas, which contains three major database materials, which are respectively Scientific Citation Index (SCI), SSCI, Art and Humanities Index and Emerging Sources Citation Index (A\&HCI). Accordingly, it has two characteristics: authoritative and fruitful [35]. Archambault et al. [36] considered the core database of WoS to be a suitable source of data for scientific measurement. Hou et al. [37] further elaborated that based on the core database, knowledge maps and knowledge domains in a specific domain can be identified, and knowledge evolution analysis can be performed. The selection of WoS database as data resource to conduct comprehensive study has been widely recognized by previous studies $[38,39]$. It is also necessary to explain that the SSCI database was selected for its inclusion in the social science literature, which is commensurate with the field of study. The SCI database contains a large amount of sewage treatment technology literature in the field of environmental science and technology, which is inconsistent with this research field. The A\&HCI database includes humanities and art literature, which is also different from this field of study. In fact, some papers in SCI and A\&HCI source journals that are related to the social sciences will also be included in SSCI. Thus, this article used the SSCI database in WoS as the basis for retrieval. Accordingly, the paper set the search time as "all years", and typed "environmental transparency" in the subject line, then got 1024 results. In order to make the analysis results accurate, some irrelevant materials were excluded in this article, such as publication advertisements, letters, submission guidelines and so on. At the same time, as a paper may cover different topics, some articles are possible to include topics other than ET, which may diverge our findings. As a result, this article also adopted a dual expert discussion method to individually review selected articles. That is, two researchers with professional experience in the ET field independently read and checked the references according to the standards, and discussed any differences until a consensus have been reached. Finally, the author saved a total of 930 screened papers with the theme of ET and standardized them. Namely, the full record of each paper in WoS contains the following basic information: author, title, abstract, keywords, publication year and references. Similarly, each retrieved reference includes the name of the first author, year of publication, type of source, journal number, volume number, and DOI.

\section{Yealy number of papers}

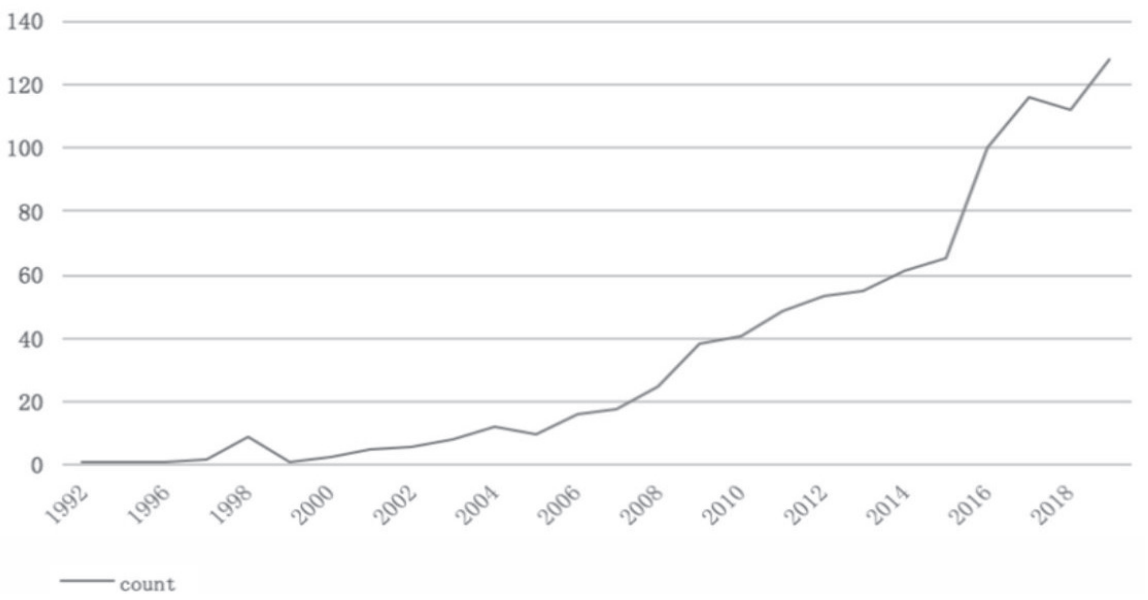

Fig. 1. Yearly number of published papers on ET. 
Thereby, the similar basic information can be used as the basis for finding the inner connection of the literature. Descriptive statistics of the number of papers published each year is shown as Fig. 1. The literature on ET started in 1992, and the number of publications each year has increased almost year after year. Specifically, the number of publications has maintained a steady increase since 2000, and the number of publications after 2014 has begun to rise sharply. It can be seen that the research on ET has been concerned by more and more scholars, especially in recent years, due to the increasing importance of ET, the scope of its research have also been continuously expanded (e.g. [40]).

\section{Methods}

The bibliographic map of ET can be explained through various networks established by CiteSpace, such as co-occurring keywords and co-cited literatures. This article mainly analyzes from the following aspects: keyword co-occurrence network based on highfrequency keywords, literature co-citation network, clustering network, and ET knowledge evolution model.

First, Small \& Griffith [41] proposed that co-word analysis has certain similarity with co-occurrence analysis. It is a method of content analysis, which can show the relationship of research structure and relations among topics through the analysis of the terms appear in the same literature $[42,43]$. Bibliometrics is based on the following two assumptions: if two keywords appear at the same period, they have relation [12], and the keywords of the paper are considered to be adequately described and best summarized the main components [44]. The keyword co-occurrence network is based on the above assumptions and is used to detect keywords that appear in at least two different papers within a period of time [45]. Today, many scholars have used coword analysis to analyze research advances in different disciplines (e.g. [46]). As the basis of the ET literature, these high-frequency keywords and the keyword cooccurrence network can be considered as part of the ET knowledge base.

Secondly, exploring the knowledge domain of ET based on the knowledge base of ET is of great significance to understand the research hotspots and evolution trends in this field. As early as the last century, Small [47] and McCain [48] have proposed co-citation analysis methods. If scholars repeatedly cited certain literature in a research field, these relatively frequently cited literature can be considered as important references for research in this field [10]. These papers with high citation rates can be obtained by co-citation analysis. In addition, cluster analysis is based on the idea of "similar things are categorized together". According to the attributes of the indicators, group the indicators with high similarity into one category. The basic requirement is to minimize the internal differences between similar indicators and maximize the difference between categories [49].
Specifically, it is an analysis method that classifies research objects based on their characteristics according to certain criteria [30]. The basic idea is that there are different degrees of similarity (intimacy) between individuals, that is, individuals within a group have a high degree of similarity, and there are differences between groups. Cluster analysis is to aggregate the variables with similarity into one category, and other variables with high similarity into another category. Consequently, this article aggregated all variables to form a small-to-large classification system, and uses pedigree maps, network views, or density views to indicate the affinity between all variables [50]. It can be understood that two papers are often cited at the same time, then they may be related to similar concepts and have a close relationship. Through cluster analysis, papers with internal connections can be identified. By using CiteSpace, they can be aggregated into clusters based on their interconnectivity. Different clusters represent a different knowledge domain and vice versa [51]. The connection between different clusters reflects their correlation in this study [14, 44].

Thirdly, in order to examine the trend of literature research topics, this article also draws time zone map. The map used the year in which the keywords appear as marked points and the frequency of occurrence as a cumulative amount, which can better reflect the theme change and evolution of China's ET. On the basis of this, the keywords burst knowledge map is drawn, and the internal research hotspots of each evolution stage are analyzed.

Finally, on the basis of keyword network analysis, this research uses CiteSpace to identify references with strong citation bursts to discover changes in research hotspots in ET and analyze current research frontiers. Strong citation bursts analysis is based on the following assumptions: if a paper is frequently cited within a certain period of time, the paper will be considered as a reference paper with strong citation bursts, and it can also be understood as a landmark paper in the development of ET [10]. The nodes of strong bursts indicate that these papers have received special attention during the corresponding time period, and can reflect the evolutionary trend of the frontier and hot spots of the discipline to some extent [45].

\section{Results and Discussion}

This paper mainly elaborates the research results from three aspects: knowledge domain, knowledge base, and knowledge evolution. It aims to build a knowledge graph of ET based on the three aspects.

\section{Knowledge Base}

Knowledge base is based on high-frequency keywords that appear in the literature. This section will first introduce high-frequency keywords in the 
field of ET. Then, based on high-frequency keywords, a keyword co-occurrence network is generated, that is, a knowledge map of ET to discover the knowledge structure in the field.

\section{High Frequency Keywords}

As the keywords of a paper can well summarize the main content [44], and the analysis of the frequency of keywords can help capture the core and hotspots of ET research. The statistical function of keyword frequency in CiteSpace is applied to analyze the frequency of keywords in the selected 930 sources of reference. After repeated calculations of the threshold through CiteSpace, the following table shows 45 high frequency keywords (see Table 1) that occur more than 15 times. If the threshold is set higher than 15 , it will miss many critical sources. If the frequency of keywords is set lower than 15, the number of literature and keywords included will be too large to perform a concise and effective co-word analysis. These keywords can be considered as an important basis for ET knowledge formation, as the higher frequency of a keyword means it has attached more importance in the existing research [44]. As can be seen from the Table 1, the most commonly used keywords (frequency greater than 100) are as follows: transparency (157 times), governance (108 times), management (108 times); sustainability (103 times). It is understandable that these most used keywords play important roles in the research of ET. These data showed a certain extent that ET is closely related to the topics of environmental management and environmental governance and sustainability. These keywords will be used as knowledge base, which will lay the foundation for further analysis of keyword cooccurrence networks analysis.

\section{Keyword Co-Occurrence Network}

The above reflects the knowledge base of ET to some extent. However, the frequency analysis of keywords appearing in the literature cannot reveal the relationship between the keywords, nor can they explore the inherent structure of the current literature on ET

Table 1. High frequency and high mediating keywords in the field of ET (Frequency $>15$ ).

\begin{tabular}{|c|c|c|c|c|c|}
\hline & Keyword & Freq. & Rank & Keyword & Freq. \\
\hline 1 & Transparency & 157 & 24 & Sustainable development & 31 \\
\hline 2 & Governance & 108 & 25 & Quality & 29 \\
\hline 3 & Management & 108 & 26 & Decision making & 27 \\
\hline 4 & Sustainability & 103 & 27 & Environmental disclosure & 24 \\
\hline 5 & Corporate social responsibility & 99 & 28 & Perspective & 24 \\
\hline 6 & Performance & 78 & 29 & Public participation & 23 \\
\hline 7 & Policy & 75 & 30 & Uncertainty & 23 \\
\hline 8 & Impact & 67 & 31 & Indicator & 23 \\
\hline 9 & Disclosure & 63 & 32 & Organization & 22 \\
\hline 10 & Accountability & 62 & 33 & Knowledge & 22 \\
\hline 11 & Legitimacy & 58 & 34 & Social responsibility & 21 \\
\hline 12 & Framework & 58 & 35 & Biodiversity & 21 \\
\hline 13 & Information & 56 & 36 & Firm & 20 \\
\hline 14 & Participation & 51 & 37 & Stakeholder & 20 \\
\hline 15 & Climate change & 47 & 38 & Lesson & 19 \\
\hline 16 & Science & 44 & 39 & Responsibility & 18 \\
\hline 17 & Model & 43 & 40 & Information disclosure & 18 \\
\hline 18 & China & 41 & 41 & Strategy & 18 \\
\hline 19 & Conservation & 38 & 42 & Power & 17 \\
\hline 20 & Environmental governance & 36 & 43 & Environmental management & 16 \\
\hline 21 & System & 34 & 44 & Standard & 16 \\
\hline 22 & Politics & 33 & 45 & Environmental performance & 16 \\
\hline 23 & Determinant & 33 & & & \\
\hline
\end{tabular}




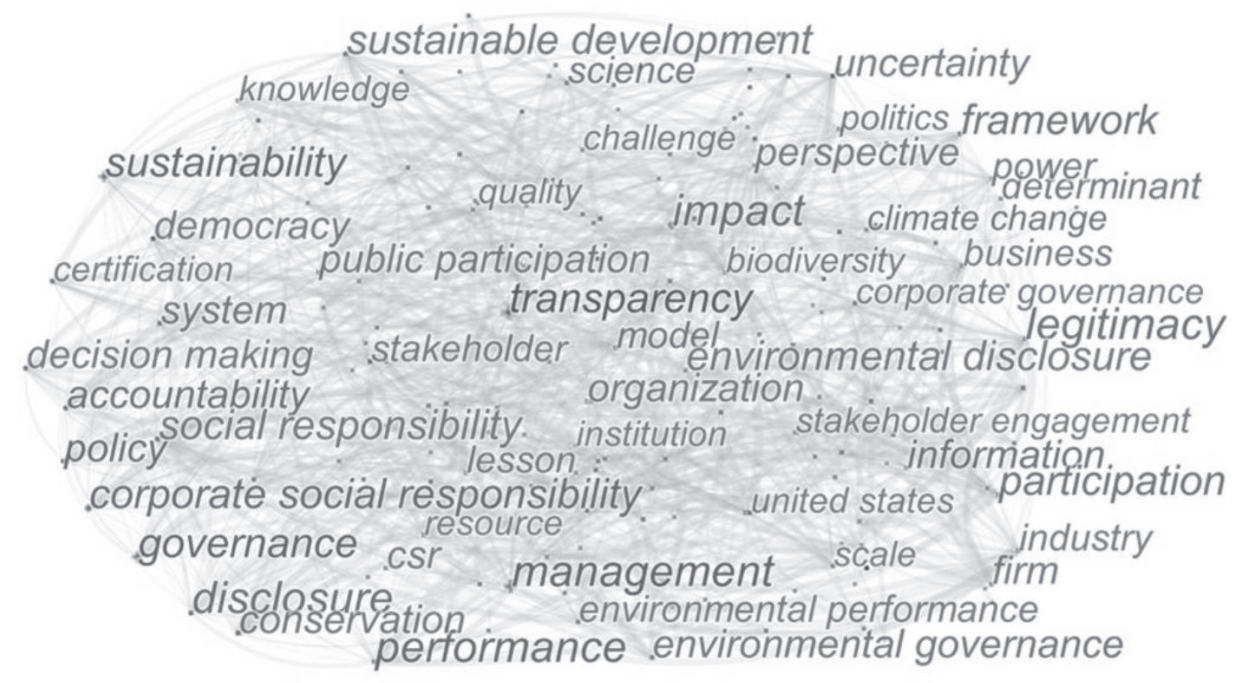

Fig. 2. Keywords co-occurrence network (knowledge map) of ET.

topics. Therefore, it is necessary to conduct further co-occurrence analysis on keywords appearing in the literature, and to produce a co-occurrence network of keywords to show the knowledge map in the field of ET research. The keyword co-occurrence network is on the basis of high frequency keywords, which can show the inherent relation between these keywords $[12,43]$. Fig. 2 presents the keywords co-occurrence network with 190 nodes and 1110 links based on the high-frequency keywords with frequency greater than 15 shown in Table 1, by using the function of keywords co-occurrence of CiteSpace software. In the map, the nodes represent keywords and the lines represent the internal connections of keywords [18]. Also, the font size of the keywords in the figure is directly proportional to the co-occurrence frequency of the keywords [52], which helps to understand the current focus of ET research.

In the analysis of keyword co-occurrence network, centrality is one of the main indicators for measuring the power, influence, or individual properties of a keyword [18]. In particular, the degree of centrality indicates the degree to which a given keyword is directly related to other keywords. If a keyword (node) has more links to other keywords, then that keyword is likely to be the core of a popular topic [44]. Closely related keywords are at the center, while loose keywords are at the periphery, suggesting the hierarchical nature of ET research [14]. It means that the keywords, like transparency, impact, environmental disclosure and stakeholder, received widespread attention in the existing research of ET. Note that these nodes at the periphery are not the current focus, however, they may become potential hot themes in the future. During the analysis process of CiteSpace, the density is used as an indicator to measure the strength of interactions between those high frequency keywords [51]. The network density of Fig. 2 is $0.018(>0.01)$, which indicates that it is strong for the connections among the above high frequency keywords [10], meaning that these high frequency keywords are often discussed with each other in existing researches.

\section{Knowledge Domain}

The Knowledge Domain is composed of two parts: Literature Co-Citation Analysis and Cluster Identification and Analysis. It is a further summary based on the knowledge base to analyze the research paradigm and category of the current ET, so as to clearly understand the knowledge domain.

\section{Literature Co-Citation Analysis}

If two (or more) papers are cited by one or more later papers at the same time, they are considered to constitute a co-citation relationship [53]. Using the function of literature co-citation analysis in CiteSpace to visually analyze the co-citation status of the selected 930 articles, a common citation network containing 784 nodes and 2796 connections can be obtained (see Fig. 3). In the network, nodes represent citations to papers in the SSCI database, and links represent cocitation relationships between one node and another [54]. The larger the node, the higher the frequency of citing the literature, indicating that the literature is more important in the study of ET [54]. CiteSpace can divide the timeline of papers published so far into a series of time periods. This work selects each time period as a year, to find out the most influential literature in each year, which can make the results of literature cocitation analysis more accuracy and comprehensive. By referring to the previous experience [10], the top 50 literature cited most frequently in each time period were selected for co-citation analysis, and then a cocitation network was generated. This article selects the first 8 frequently cited papers (frequency greater than 


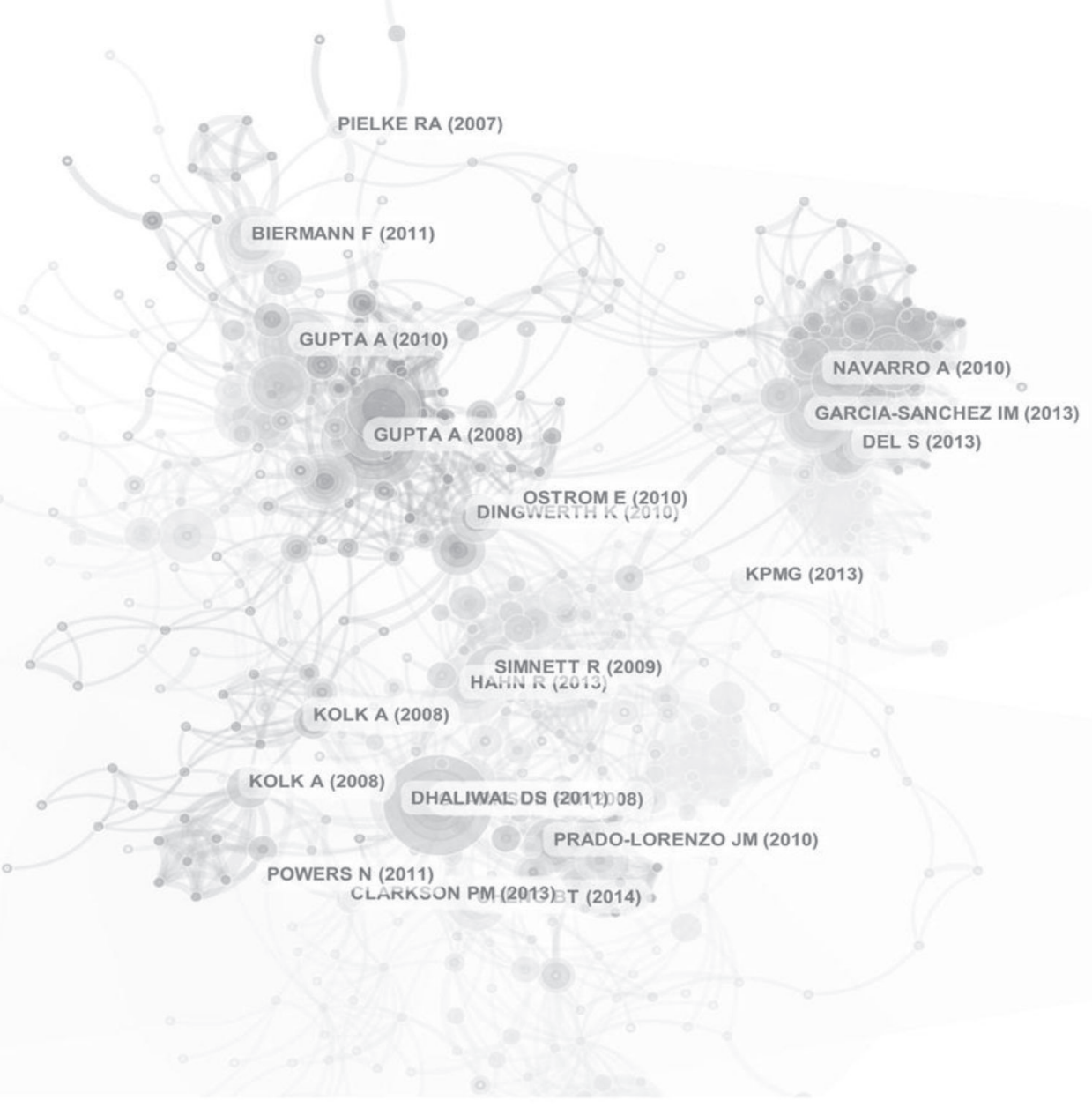

Fig. 3. Literature co-citation network of ET.

Table 2. Top 8 frequent co-cited articles in the ET field.

\begin{tabular}{|c|c|c|c|c|}
\hline Author & Title & Year & Frequency & Source \\
\hline Gupta, A. & $\begin{array}{l}\text { Transparency Under Scrutiny: Information } \\
\text { Disclosure in Global Environmental Governance }\end{array}$ & 2008 & 18 & $\begin{array}{l}\text { Global Environmen- } \\
\text { tal Politics }\end{array}$ \\
\hline $\begin{array}{l}\text { Clarkson P.M., Li Y., } \\
\text { Richardson G.D., Vasvari P. }\end{array}$ & $\begin{array}{l}\text { Revisiting the relation between environmental } \\
\text { performance and environmental disclosure: } \\
\text { An empirical analysis }\end{array}$ & 2008 & 18 & $\begin{array}{l}\text { Accounting, } \\
\text { Organizations and } \\
\text { Society }\end{array}$ \\
\hline Gupta A. & $\begin{array}{l}\text { Transparencyin global environmental governance: } \\
\text { a coming of age? }\end{array}$ & 2010 & 14 & $\begin{array}{l}\text { Global } \\
\text { Environmental } \\
\text { Politics }\end{array}$ \\
\hline $\begin{array}{l}\text { Dahliwal D.S., Li O.Z., } \\
\text { Tsang A., Yang Y.G. }\end{array}$ & $\begin{array}{c}\text { Voluntary Nonfinancial Disclosure and the Cost of } \\
\text { Equity Capital: The Initiation of Corporate Social } \\
\text { Responsibility Reporting }\end{array}$ & 2011 & 14 & $\begin{array}{l}\text { The Accounting } \\
\text { Review }\end{array}$ \\
\hline Biermann F., Gupta A. & $\begin{array}{l}\text { Accountability and legitimacy in earth system gov- } \\
\text { ernance: A research framework }\end{array}$ & 2011 & 13 & $\begin{array}{l}\text { Ecological Econom- } \\
\text { ics }\end{array}$ \\
\hline Hahn R., Kuhnen M. & $\begin{array}{l}\text { Determinants of sustainability reporting: a review } \\
\text { of results, trends, theory, and opportunities in an } \\
\text { expanding field of research }\end{array}$ & 2013 & 13 & $\begin{array}{l}\text { Journal of Cleaner } \\
\text { Production }\end{array}$ \\
\hline $\begin{array}{l}\text { Navarro A., Alcaraz F.J., } \\
\text { Ortiz D. }\end{array}$ & $\begin{array}{l}\text { The Disclosure of Corporate Social Responsibility } \\
\text { Information in Public Administrations: An Empirical } \\
\text { Study in Local Governments }\end{array}$ & 2010 & 13 & $\begin{array}{l}\text { Revista de Contabi- } \\
\text { lidad }\end{array}$ \\
\hline $\begin{array}{l}\text { Garcia-Sanchez I.M., } \\
\text { Frias-Aceituno J.V., } \\
\text { Rodriguez-Dominguez L. }\end{array}$ & $\begin{array}{l}\text { Determinants of corporate social disclosure } \\
\text { in Spanish local governments }\end{array}$ & 2013 & 13 & $\begin{array}{l}\text { Journal of Cleaner } \\
\text { Production }\end{array}$ \\
\hline
\end{tabular}


12) from the network for detailed analysis (see Table 2), because more cited papers means more representation and influence [18]. These literature can reflect the research focus of ET to some extent.

Gupta [55] identified the linkage among ET, accountable, legal and effective governance, believing that ET is increasingly at the core of global environmental governance programs. Clarkson [56] developed a content analysis index based on the Global Reporting Initiative's Sustainability Reporting Guidelines to assess the extent of discretionary disclosure in environmental and social responsibility reports to improve existing literature. Compared to the index used in previous studies, the index better reflects corporate information related to protecting the environment. Using a sample of 191 corporations from five of the most polluting industries in the United States, it found a positive correlation between environmental performance and the environment as appropriate for disclosure. The results are consistent with the predictions of the economic disclosure theory, but contradict the negative associations predicted by the sociopolitical theory. Gupta [57] answered three questions when considering the impact of the shift towards transparency on global environment and sustainable governance: Why is transparency now? How is transparency institutionalized? What does it do? He believes that the impact of ET (whether it is informing, empowering, or improving environmental performance) is still uneven, and transparency has failed to achieve what many people expect. However, ET has indeed become a defining feature of our current and future politics. Dahliwal et al. [58] examined the potential benefits associated with voluntary disclosure of corporate social responsibility (CSR) activities: reducing the corporation's equity cost. It found that corporations with a higher cost of equity capital in the previous year tended to initiate disclosure of corporate social responsibility activities in that year, while a sponsoring corporation with a higher social responsibility performance would subsequently reduce the cost of equity capital. In addition, startups with outstanding social responsibility performance attract specialized institutional investors and analysts. Moreover, these analysts have lower absolute forecast errors and dispersion. Finally, they also found that corporations took advantage of the lower cost of equity associated with initiating corporate social responsibility disclosure. After the launch, the sponsoring corporation is more likely to raise equity capital than the nonsponsoring corporation. Among the corporations that raise equity capital, the sponsoring corporation raises much more capital than the non-sponsoring corporation Biermann \& Gupta [59] elaborated on sources, mechanisms and reforms related to more accountable, legal and democratic ecosystem governance. Their research found that ecosystem transformation poses daunting accountability and legitimacy challenges. Defining stakeholders in ecosystem governance is a key responsibility challenge. The relationship between the legality of inputs and outputs varies from environment to environment. Reform of decision-making procedures must be undertaken to increase accountability and legitimacy. In particular, the influence of civil society actors in the intergovernmental system should be strengthened. Hahn \& Kuhnen [60] provided a systematic review of 178 sustainability topics in the business, management, and accounting fields from 1999 to 2011. Studies have found that there is usually no existing relationship between legitimacy, stakeholders, signals, and institutional theory. Moreover, the current research on sustainable development should strengthen considerations including supervision, governance, quality of information disclosure and stakeholder participation. Navarro et al. [61] analyzed the websites of 55 large local governments and came to conclusions about the disclosure of general CSR information and the release of economic, social and environmental information. The results show that the main shortcomings of corporate social responsibility disclosure are related to environmental information, and social information is the most public. Similarly, the size of the entity, political competition, and political signs of the government cannot explain the development of CSR information disclosure. Garcia-Sanchez et al. [62] analyzed the content of the websites of 102 Spanish local governments. Different statistical techniques (double-line diagrams and dependency models) were used to analyze the extent of disclosure and determine the impact of certain contextual and political factors on ET. Compared with the amount of information disclosed on financial issues, the disclosure of social and environmental information is scarce. It also observed that the existence of conservative governments and political competition could be a real obstacle to municipal transparency. Based on these findings, they made two policy recommendations. First, it is necessary to formulate national policies, laws or recommendations to generate a similar degree of transparency among local governments to avoid social dilemmas. In this sense, similar accountability processes limit unsustainable behavior and play a similar role to private sector markets. Second, the accountability process should focus on increasing information about social and environmental actions and informing municipalities about their impact, not just the strict economic scope.

By elaborating the above 8 frequently cited articles in the field of ET, it can find that ET is closely related with the fields of politics, business, marketing, organizational behavior, and accounting, and is a subject with a multidisciplinary nature. Scholars mostly focused on ET from government environmental regulation, corporate social responsibility, sustainable development and other aspects. This result also confirmed the results of the keyword network analysis in the previous section to some extent. In order to further confirm our conjecture, this article will perform cluster analysis on the selected 930 literature. 


\section{Cluster Identification and Analysis}

Identifying highly cited literature through literature co-citation analysis is the first step in identifying a knowledge domain, and the second step is analyzing the literature to identify key research areas. Select a cluster label from the noun phrase for each cluster. Noun phrases are extracted from the keywords of the selected 930 articles by employing the CiteSpace. The highest ranked phrases may be selected as clustering tags [14]. Keywords reflect the core content of the thesis [12]. By analyzing the clustering of keywords, the content and direction of ET research can be grasped, and the research frontier can then be explored [44]. CiteSpace provides three different types of cluster tag extraction algorithms, including log-likelihood ratio (LLR) testing, Term Frequency-Inverse Document Frequency (TF-IDF), and Mutual Information (MI) testing. According to the previous experience [10], this article uses CiteSpace's default algorithm LLR test to extract cluster labels. In statistics, a likelihood ratio test is a statistical test used for comparing the goodness of fit of two statistical models, namely, a null model and an alternative model. The test is on the basis of likelihood ratio, which denotes how many times more likely the data are fitting one model than the other. This likelihood ratio, or its equivalent logarithm, can then be used to compute a $p$-value, to decide whether or not to reject the null model [63]. The $p$-value stands for the probability of the difference between samples caused by sampling error. When the $p$-value is less than 0.01 , it means that the cluster of the selected papers is very significant and appropriate [10]. Specifically, the paper uses Citespace keyword path calculation method, sets Node Types to "Keyword", time-slicing the sample data with a time slice of 2 , and extract the top 50 keywords that appear in each time slice, select Cosine to calculate correlation strength. In order to ensure the integrity of the knowledge graph, no network pruning algorithm is used to generate a keyword co-occurrence knowledge graph (see Fig. 2). In the map, the keywords of high activity reflect research hotspots, and the degree of centrality indicates its dominance in the network. After network clustering, the LLR is used to name the clusters. There are 253 nodes in the graph, 11,778 connections, the network density is 0.00618 , the module value is $\mathrm{Q}=0.3749(>0.3)$, and the average contour value $\mathrm{S}=0.7566(>0.65)$, these show that the clustering structure is significant and the clustering is reasonable [10]. It should be noted that the network density values, module values and average contour values in the cluster analysis network are consistent with the keyword network analysis, which further illustrates the effectiveness of the cluster analysis. Fig. 4 illustrates the four cluster names obtained by CiteSpace in order of size: cluster 0 \# risk assessment, cluster 1 \# China, cluster 2 \# local government, cluster 3 \# institutional theory, these are the main research areas of ET at present.

This article further summarizes the number of articles, contour values, citation years, and LLR likelihood values included in each cluster, as shown in Table 3.

Table 3. Top-ranked clusters and the terms within the clusters. LLR-log-likAt present, the largest cluster in ET research is risk assessment, which contains 38 literature. Agathokleous et al. [64] believed that there are still unresolved issues in improving the quality of ecological risk assessment, such as consideration of adaptability, dynamics and interactions. Lueg et al.

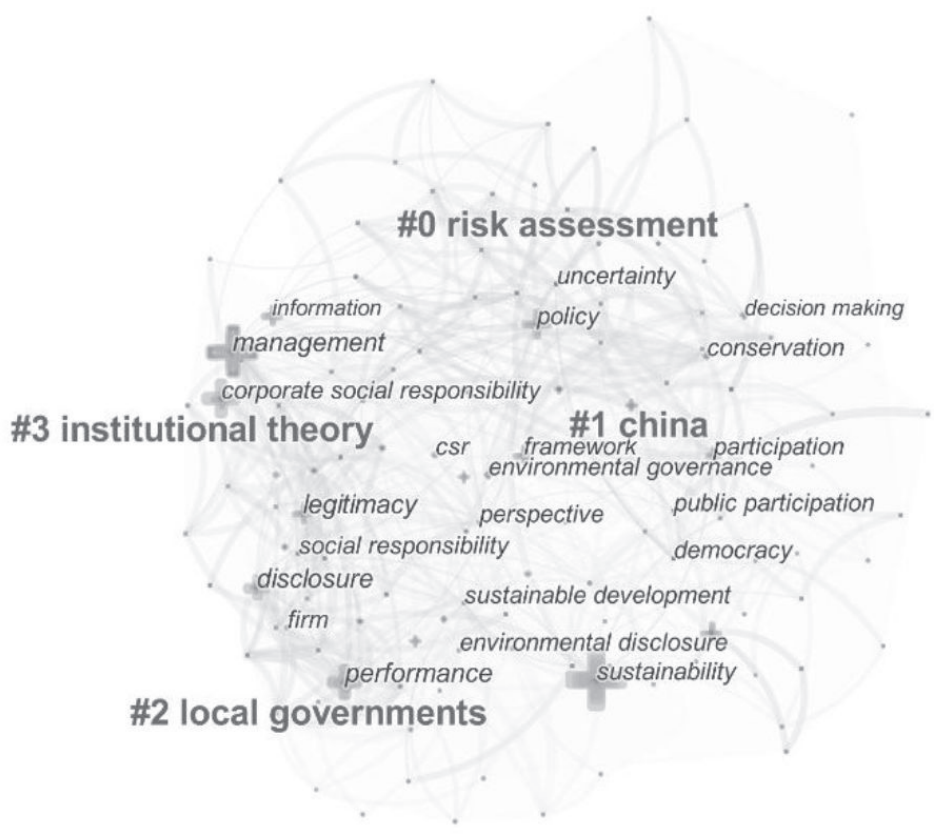

Fig. 4. Clusters of knowledge domain within ET. 
Table 3. Top-ranked clusters and the terms within the clusters. LLR-log-likelihood ratio.

\begin{tabular}{|c|c|c|c|c|}
\hline Cluster ID & Size & Silhouette & Mean (Cited Year) & Labe (LLR) $(p$-value) \\
\hline 0 & 38 & 0.742 & 2009 & $6.86,0.001$ \\
\hline 1 & 37 & 0.633 & 2009 & $14.32,0.001$ \\
\hline 2 & 33 & 0.798 & 2011 & $8.16,0.005$ \\
\hline 3 & 28 & 0.715 & 2009 & $8.51,0.005$ \\
\hline
\end{tabular}

[65] found that sustainable disclosure, especially on social sustainability issues, can reduce systemic risk in subsequent periods. In addition, other one-way and two-way effects have been identified, which indicate higher total risk, systemic risk, and idiosyncratic risk that have prompted corporations to report more social issues in subsequent periods. At the same time, preliminary evidence suggests that higher systemic risks result in less disclosure of governance issues. In general, breaking down sustainable disclosure into environmental, social, and governance issues helps to gain a deeper understanding of its two-way relationship with total, systemic, and idiosyncratic risks. The second is to study the issue of ET in China. This cluster contains 37 articles. For example, Kostka et al. [66] found that under the background that the role of information has evolved over time as the dominant environmental regulatory approach has changed, the performance of new information technologies in China has so far been simple. Although some similarities can be drawn between advanced democracies and China, many predictions about the impact of data and information technology have not yet been confirmed in China. The third cluster is a research topic on local government, which contains 33 literature that clarify the relationship between local government and ET. For example, Pache-Duran \& Nevado-Gil [67] analyzed the similarities and differences that may exist between local governments at these levels of disclosure based on social responsibility information provided by Spain's 50 provincial capitals through their websites. The fourth cluster is about the application of institutional theory to ET. This cluster contains 28 literature. For example, Van et al. [68] explored the increasing number of Vietnamese corporations that are beginning to incorporate environmental management systems into their business strategies and develop green product diversification strategies. It discusses the important role played by foreign customers in promoting the corporation to adopt a green product diversification strategy. For foreigninvested corporations, the effect is limited to the use of horizontal green product diversification.

According to the results of cluster analysis and the analysis of the above representative literature, there are several findings. First, because ET is multidisciplinary, the interpretation of risk assessment is multi-angled. For example, Agathokleous et al. [64] combined with ET by the perspective of ecological risk assessment, believing that improved risk assessments include adaptive and dynamic nonlinear models (beyond classical threshold models) can improve the quality of regulatory decisions and protect ecological health. Lueg et al. [65] studied ET from the aspects of total corporate social responsibility disclosure, systemic risk, and idiosyncratic risk, suggesting that managers would benefit from these insights by better understanding how sustainable practices and disclosing relevant information improve market assessments of corporate system risks. Investors and regulators can learn from this research that managers generally choose which reporting strategy to respond to changes in market risk perceptions. In addition, issues related to Chinese ET are also the focus of scholars' research in the field of ET. The key issue lies in the special political system of China. It is understandable that in recent years, with the enhancement of national environmental awareness, many related environmental protection policies have been introduced. the number of corporate social responsibility reports issued has increased dramatically under the compulsory requirements of national policies, and the degree of ET has also increased. However, the "authenticity" of the published information remains to be confirmed. As discussed above, ET works only if the quality of the information is guaranteed [23, 69] demonstrated that political linkages can increase the amount of corporate environmental information disclosure, while the quality of environmental disclosure is still low. In China's top-down political system, many Chinese corporations assume environmental responsibility passively [70]. Undoubtedly, in a wellestablished economy, the government's main influence on corporate environmental information disclosure comes from formal mechanisms such as laws, regulations and regulatory regulations. However, China is currently an economy in transition. The market environment for the positive signals of environmental performance has not yet formed, and corporations with good environmental information may not be able to form corresponding response mechanisms. At present, the quality of environmental disclosure in China is still far from that of developed countries, and there is no unified evaluation standard for environmental disclosure [71], which has led to low quality of environmental information disclosure. At the same time, accountability is difficult due to inconsistent assessment standards [72]. Therefore, scholars consider the deep causes of 
this problem from multiple perspectives and provide corresponding countermeasures to improve the quality of China's environmental information disclosure and strengthen the credibility of ET. Although this problem has been increasingly valued by scholars and practical organizations, it is still to be resolved, which may continue to be the focus of future ET research [69]. Furthermore, the authors found that Cluster \#2 "local government" and Cluster \#3 "institutional theory" are often combined to explore issues about ET in China's situation. According to institutional theory, China's institutional system is relatively complicated, and different administrative levels have different policies in their implementation, and the action basis of the central and local government departments are different [73]. As a result, the effective implementation of legal regulations is restricted. Wong et al. [1] supported the idea based on institutional theory that, if a region has a relatively large number of poor people, the region is more likely to sacrifice resources and the environment for economic development. Then the region's enforcement of environmental regulations (including ET) formulated by the central government is usually superficial and ineffective [74]. Also, China's environmental governance is mainly implemented locally by local environmental protection bureaus, and staffing and funding are determined by local governments. Local environmental protection bureaus have weak rights and limited resources, so environmental protection is only a matter of words [1]. Not only China, many developing countries have similar difficulties. How to make up for organizational loopholes, improve policy formulation systems and standards, reduce regional differences, and mobilize the environmental protection enthusiasm of local governments have attracted the attention of a large number of scholars [1, 72]. A number of feasible countermeasures for decision makers to address the above difficulties have been put forward in the existing literature. Firstly, the level of ET is proposed as one of the criteria for evaluating the performance of local officials [3]. This method can foster the incentives for local officials to actively implement related strategies to ET, and force local officials to attach importance to the roles of ET and strengthen the supervision on ET in a compulsory way [75]. Secondly, it is necessary to support various stakeholders, such as social groups and media, to extensively collect pollution evidence and disclose them in officially recognized websites, to form pressures on the governments, thus to inspire ethics and responsibility [76]. Thirdly, establishing a vertical management agency among environmental protection agencies below the provincial level is a way to promote supervision of ET law enforcement and strengthen local governments' environmental responsibility [77].

\section{Knowledge Evolution}

Studying the evolution of knowledge in ET can clearly explain the value of co-citation and clustering [14]. Visualizing the evolution of knowledge of ET through CiteSpace can make researchers aware of the changes in research hotspots, identify the current research frontiers, discover the shortcomings of the current research, and help provide directions for future research on ET.

\section{Research Hotspot Evolution}

In a relatively short period of time, the literature with strong internal connections are clustered together to form a research focus [78]. Keywords are the concentration and generalization of the core content of literature. A time zone map that reflects the evolution of research hotspots based on the time dimension is selected [79]. Hence, the keywords from the selected 930 articles are used to track research hotspots at different stages via the time zone map function of CiteSpace. In order to ensure the integrity of the graph,

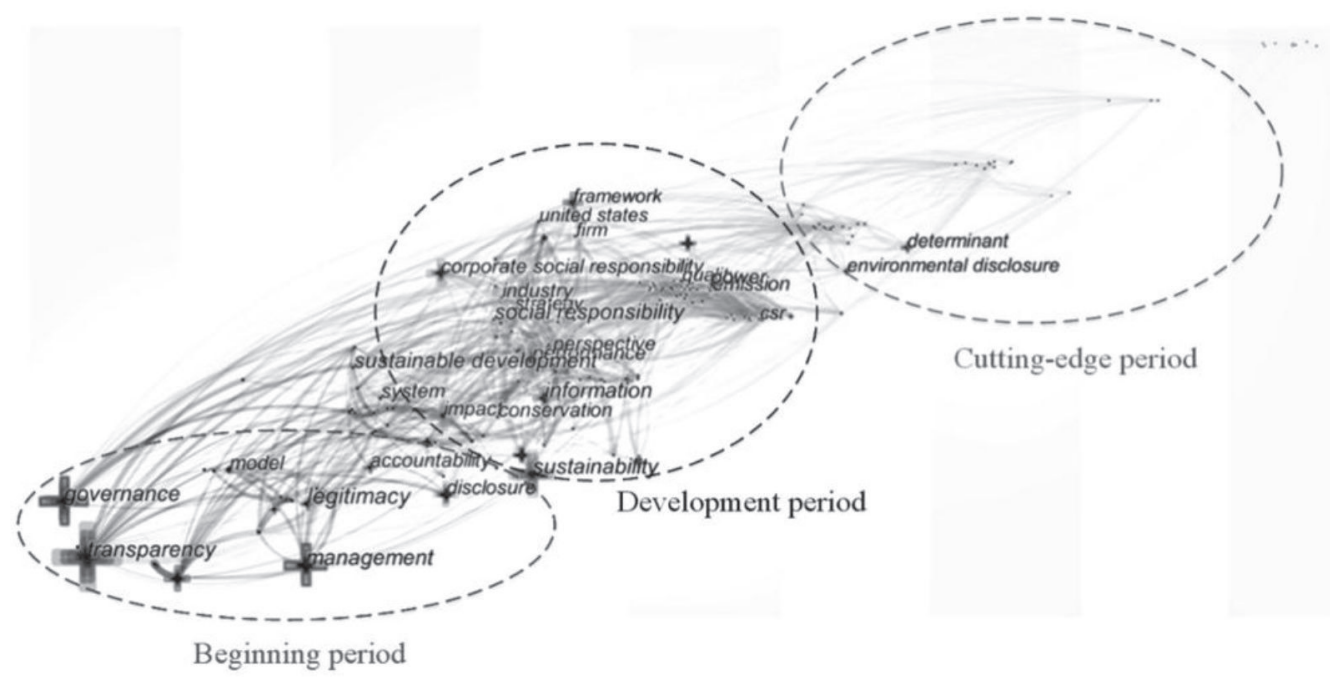

Fig. 5. The keywords co-occurrence time zone map in relation to the ET research field. 
no network trimming algorithm is used, and other settings remain unchanged. Select "Time Zone" in the visual interface. To effectively display the key nodes, only the nodes with frequency $\geq 6$ are displayed. The graph is obtained as shown in Fig. 5.

As time progresses, the pattern of keywords continues to alternate. Based on the keyword cooccurrence time zone map, this paper finds that ET research has gone through three stages. First, in the nascent stage, countries began to realize the need for ET and tried to apply it to governmentled environmental governance, environmental law, and environmental accountability. However, Gupta [55] points out that although ET is a key concept in our times, it is still a relatively under-appreciated phenomenon in global environmental politics. With the continuous deepening of the awareness of sustainable development, the research on ET has begun to enter the development period, and its research theme has been further extended. Research topics around corporations, such as corporate social responsibility, have become new research trends. Because corporations are the main sources of pollution, they often need to assume major responsibilities in environmental issues [80]; With the widespread application of environmental information disclosure systems in various fields in different countries, especially the positive impact of environmental transparent information disclosure on environmental policies, environmental governance, corporate environmental responsibility, and regulating corporate environmental behavior is widely recognized [81]. The topics related to ET information disclosure have gradually become an emerging hotspot and cutting edge point in ET research. The paper found that this frontier is closely related to the effect of ET policy implementation. By collating the relevant related literature in recent years, it is found that most scholars explain the policy impact of corporate environmental information disclosure based on agency theory, legitimacy theory, and resource dependence theory [82]. At present, developed countries have reached a consensus on environmental information disclosure research. Scholars believe that external regulatory pressures can strengthen corporate environmental behavior and increase ET [24, 81, 83]. The external regulatory pressures include the regulations and laws from governments and the environmental demands from other stakeholders (like the public, investors and so on) $[84,85]$. As a result, the improvement of ET related laws and the construction of active supervisions channels for other stakeholders should be attached great importance in the future [86, 87]. Firstly, setting the level of environmental information disclosure as a standard for policy rewards and penalties of an organization can be considered. The previous studies have pointed out that the number of environmental responsibility reports of organizations has increased sharply with the introduction of ET requirements [69]. Secondly, in multimedia era, ensuring the effectiveness of ET particularly needs the participation and supervision of multimedia, as it provides more regulatory channels, and the ET problems exposed by the media can often cause great concern of the whole society [88].

\section{Research Frontier Analysis}

Scientific development can be extracted from the keywords of published articles through its footprint, and keywords with transition phenomena have both the forward-looking and exploratory nature of this stage of research. Strong citation burst indicates that the scientific community has paid special attention to these articles during a certain period [89]. The study and analysis of strong citation burst literature can further understand the status and hotspots of related research. Thus, this article uses CiteSpace to visually analyze the frequency of keywords of the selected 930 articles, to identify the keywords with strong citation bursts. According to CiteSpace's existing capabilities, there are two ways to sort citations with citation bursts: by the start time of the outbreak and the intensity of the outbreak. This article chose to sort by the start time. Figure 6 shows the beginning and end time of the emergence and the first 22 emergent keywords of the emergence intensity. These emergences started in 2001 and reached their peak in the past 5 years. Environmental performance; Environment; Biodiversity etc. have become highprofile popular word frequencies in recent years. Through further induction and summary, it is found that the following latest developments and development trends exist in the study of ET.

- Governance of environmental and ecological issues is the subject of constant research on ET. With the increasing demands for green products, green services and sustainable development, the green development models have been emphasized in many countries (e.g. [90]). Coupled with the government's efforts to encourage corporations to improve their environmental assessment systems and require disclosure of environmental information, stakeholders' research on ET has become more and more concerned [3]. For example: Li \& $\mathrm{Li}$ [22] research believes that in the long run, the transparency of environmental information must conform to both the green growth framework and the long-term development goal of building green energy. Peng et al. [4] empirically tested the relationship between actual and perceived air pollution and the moderating effect of ET on this relationship.

- Accountability and environmental information disclosure are the foundation for achieving ET. Transparency through information disclosure is increasingly at the core of many global environmental governance programs [55]. An empirical assessment of preliminary data indicates that Black and Smelly Waters is a means to increase 
transparency and accountability. They believe that information and communication technology (ICT) provides a new avenue for transparency through an itemized disclosure plan aimed at improving citizens' participation in China's environmental management and policies. Tan [91] studied the impact of ET regulations in the context of China's fragmented environmental management system by studying ET measures in China. He found that given China's authoritarian structure, improved governance does not translate into stronger accountability, which challenges common assumptions about the relationship between transparency and accountability.

- An ET system led by the government and involving stakeholders. Peng et al. [4] found that the ET of local governments can mitigate the relationship between actual air pollution and perceived air pollution by eliminating halo effects and establishing a more sensitive perception when local air quality deteriorates. Jacoby et al. [92] used a sample of 4,195 observations from 19 emerging markets to investigate how internal corporate governance, external monitoring, and the legal and business environment collectively affect the effectiveness of corporations' management of environmental information transparency in an international environment. The study found that internal corporate governance mechanisms can directly improve a corporate's transparency on environmental damage and can indirectly increase transparency through external control measures.

According to the above analysis, it is necessary to strengthen the ET governance system in the future. Firstly, improving the related laws and regulations of ET and strengthening the roles of accountability and environmental information disclosure are necessary. Only by filling the loopholes in law and implementing the laws related to ET more efficiently in practice can we better ensure the effective of ET. Secondly, the governance system cannot only rely on the laws and regulations from the governments, the participation of multiple stakeholders als plays an important role for the ET improvement [93]. It should be considered

\section{Top 22 Keywords with the Strongest Citation Burst}

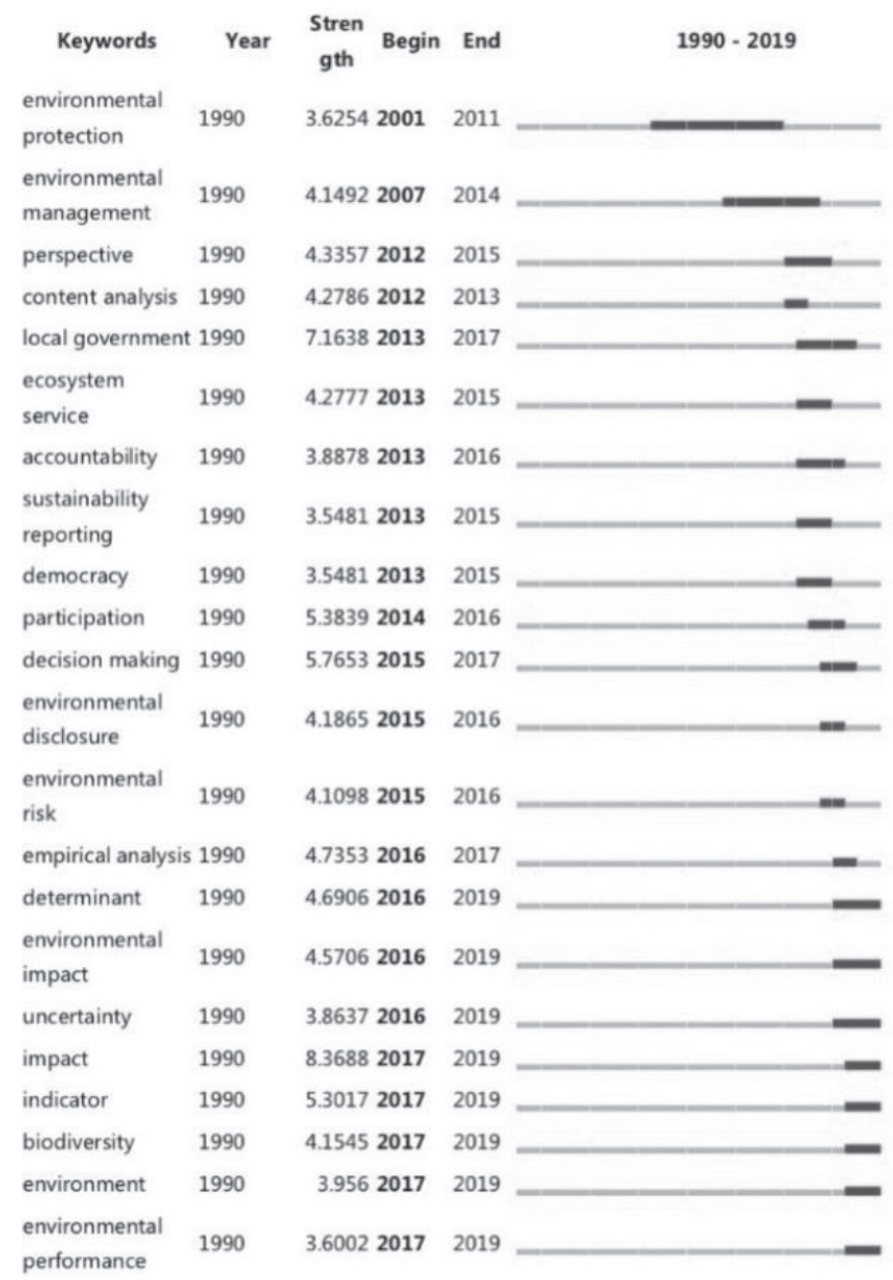

Fig. 6. Top 22 Burst terms in the study of ET. 
to establish a collaboration governance network involving in multiple stakeholders on the basis of the advancement of communication technology [88]. Thirdly, most stakeholders as the front-line perceivers are likely to more quickly sense the defects of ET, but few of them are willing to report to the governments as their awareness of ET is generally weak [94]. Thus it is necessary to enhance the awareness of ET of the public and encourage them to actively participate in the supervision of ET. In the case, the government should increase the publicity of the importance of ET and form a better atmosphere for everyone to participate in ET.

\section{Constructing Knowledge Graph for ET}

The bibliometric method can be used to clearly visualize and analyze the knowledge base, knowledge domain, and knowledge evolution of ET. This paper integrates it to build a knowledge map for ET, as is shown in Fig. 7, which is composed of knowledge base, knowledge domain and knowledge evolution. By analyzing the knowledge base, knowledge domain, and knowledge evolution of ET, researchers can understand the knowledge framework and development process of the discipline.

The knowledge base of ET includes the highfrequency keywords identified by co-occurrence networks, clustering analysis on keywords in the knowledge base to determine the field of ET knowledge, which helps better understand the main research areas of ET, including risk assessment, China, local government, institutional theory, British Columbia and impact. The evolution of knowledge of ET is briefly described below. In the early days of ET, most scholars focused on environmental protection and environmental management (2001-2007); With the deepening of ET

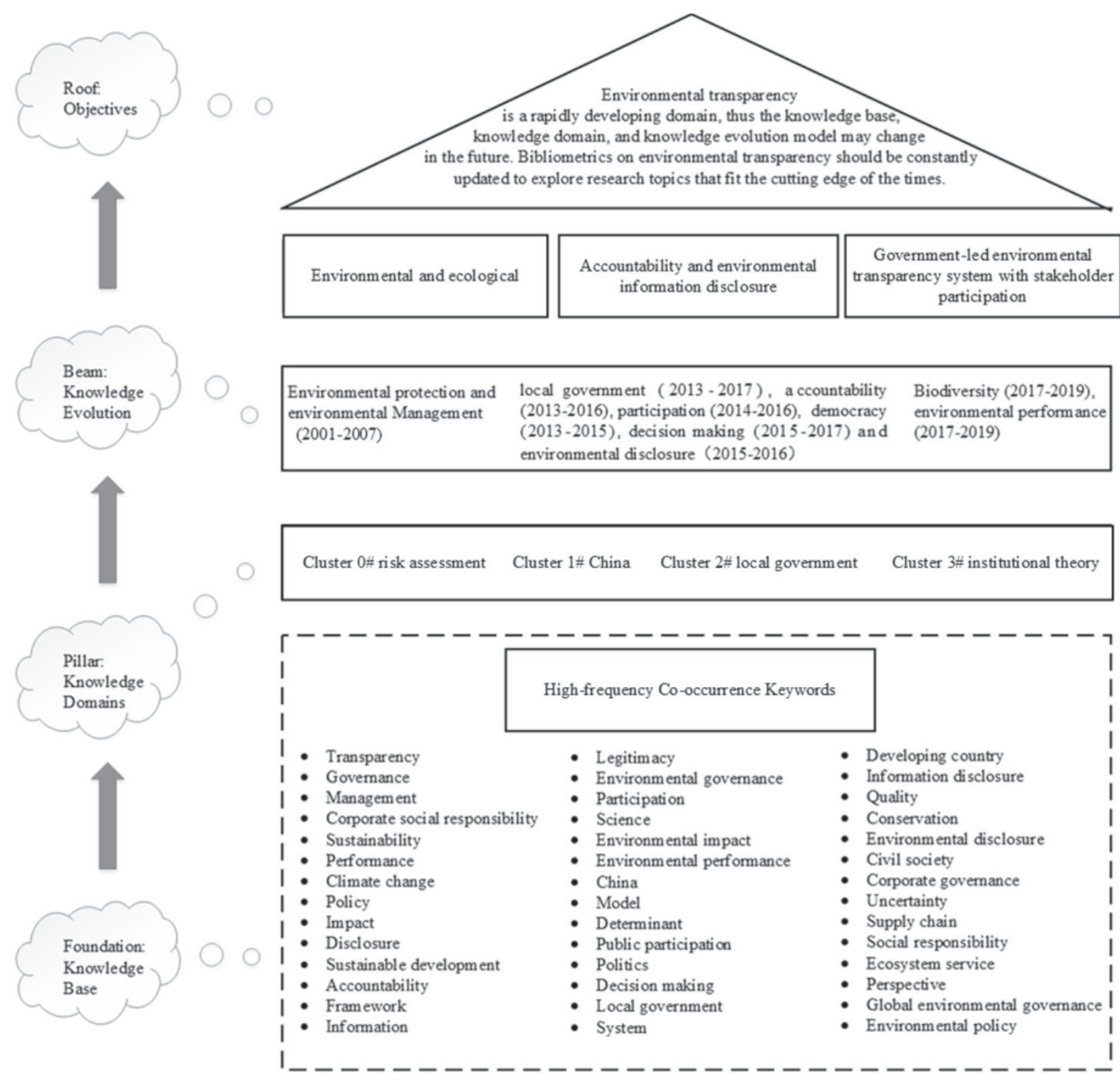

Fig. 7. A Knowledge graph of ET. 
as a tool for government environmental management and the formation of an environmental governance system with the participation of stakeholders, local government (2013-2017), accountability (2013-2016), participation (2014-2016), democracy (2013-2015), decision making (2015-2017) and environmental disclosure (2015-2016) have gradually become research focuses. Then, as countries attach more and more importance to the environment, environmental performance (environmental performance: 2017-2019) such as the protection of biodiversity (2017-2019) has become an issue of increasing concern. Further analysis of the evolution of ET reveals that research in this field has always been centered on three topics, that is, (1) governance of environmental and ecological issues; (2) accountability and environmental information disclosure are means to achieve ET; (3) the government is an environmental governance system in which ET leaders and stakeholders participate together.

Based on the above analysis combining with the knowledge storage, this paper point out the research gaps in the current research, which may be the focus of future studies in the ET field. First, as mentioned in the cluster analysis above, scholars have considered from many perspectives and conclude that China's special political system is a deep-rooted cause for blocking ET, and provide corresponding countermeasures. However, this issue remains to be resolved. Therefore, it is necessary to summarize the important factors that how to the human factors lead to ET become a superficial behavior. The mind mapping, social network analysis tools, coupling and embedding theories can be employed to build stakeholder system models to depict the conceptualized participant interaction system formed around the human-induced processes that block the performance of ET, revealing the institutional relationship, organizational relationship and interest relationship formed by each subject around the induction process of ET implementation obstacles. Second, this paper found that the current research on ET is mostly quantitative research methods (e.g. [67]). However, in-depth analysis of a problem requires the integration of multiple perspectives and methods, such as macro and micro, qualitative and quantitative. As a result, it is necessary to integrate the research methods of microstructure and qualitative analysis into the research of ET. To be more specific, the case study might be a feasible qualitative approaches for future studies. Many studies have employed case study to find out human factors for environmental pollution or other environmental problems (e.g. [87, 95]). The method is ideal when researchers hope to conduct a comprehensive and in-depth study of context-related social phenomena [96] and explore various hidden problems [97]. Third, China has a big gap with developed countries in terms of environmental disclosure quality and ET implementation effect. As Kostka et al. [66] put forward when discussing the impact of information technology on environmental regulation, although some similarities can be drawn between advanced democracies and China, many predictions about the impact have not been seen in China. Although one may actively learn from the ET experience of developed countries, it should compare the specific differences between developing countries and developed countries and ponder the reasons for the differences, so that it is possible to find the most suitable path based on the real situation of a developing country. The grounded theory can be paid more attention to address the issue. It is a set of rigorous research procedures leading to conceptual categories. These concepts or categories are related to each other as a theoretical explanation of the actions that continually resolves the main concern of the participants in a substantive area [98]. These three noteworthy issues will also be directions for future studies. It should be noted that this knowledge graph is rapidly developing and frequently expanding new research fields. Thereby, the knowledge base, knowledge domain, and knowledge evolution model may change in the future. Bibliometrics on ET should be constantly updated to explore research topics that fit the forefront of the times.

\section{Conclusions}

Based on the screening of 930 papers on ET in the SSCI database in WoS, this article applies CiteSpace to analyze the existing knowledge system of ET and draws the following conclusions.

Firstly, this article uses the function of keyword co-occurrence analysis to determine the keywords of the ET knowledge base, including 45 high-frequency keywords with a frequency greater than 15 such as transparency, governance, management, corporate social responsibility, and sustainability. A highfrequency keyword co-occurrence network was further generated based on the high-frequency keywords. It plays an important role in building a knowledge base of ET and helps scholars in this field to quickly understand the knowledge structure in the field of ET research. Secondly, four major research clusters in ET field is classified, that is, (1) risk assessment, (2) China, (3) local government, and (4) institutional theory. Through further analysis, this paper finds that: first, ET is multidisciplinary, and the interpretation of risk assessment in the existing literature is multidimensional, including ecological environment risk assessment, corporate CSR risk assessment, and so on. Second, many studies have focused on China's ET issues. These issues are often discussed in conjunction with local government and institutional theory. Since China is the second largest economy in the world but facing serious environmental issues, the research results related to its ET can generally provide references for other emerging economies to promote ET practices in future development. The value of co-citation clusters is explained for capture research frontier. 
A time zone map that reflects the evolution of research hotspots based on the time dimension is provided, and the knowledge evolution of ET is analyzed by citing citations, revealing how research related to ET has evolved over time. Research hotspots of ET are constantly changing. The three ways to achieve ET are (1) Governance of environmental and ecological issues; (2) Accountability and responsible environmental information disclosure; (3) An ET system led by the government with all stakeholders involved together is a focus of ET research. Accordingly, the paper proposed three recommendations for decision makers to ensure the feasibility of the above mentioned three ways, which are respectively improving the related laws and regulations of ET and strengthening the roles of accountability and environmental information disclosure, establishing a collaboration governance network involving in multiple stakeholders on the basis of the advancement of communication technology, and enhancing the awareness and participation willingness of the public. In addition, by constructing an ET knowledge graph, this paper pointed out three main gaps in current research. The first is investigating the mechanism of human factor that blocks the effectiveness of ET. The paper provided some methods, such as mind mapping, social network analysis tools, coupling and embedding theories, to fill in the gaps. The second is to study ET through the integration of multiple perspectives and methods, such as macro and micro, qualitative and quantitative, etc. The case study is especially suggested for future qualitative study as it has advantages in exploring various hidden problems of social phenomena. The third is to consider specific conditions of a developing country to design a peculiar pattern for its ET development. The grounded theory is suggested to achieve the goal.

CiteSpace's quantitative analysis function facilitate building a knowledge graph for the study of ET based on keywords, clustering, temporal dimensions, and citation bursts. Specifically, this article (a) identifies knowledge base and knowledge domain through emerging research frontier terms, (b) explains the value of co-citation clusters based on research frontier concepts, (c) greatly reduces the complicacy of the visualization network via CiteSpace. The combination of knowledge graph modeling and visualization enables this article to build a comprehensive knowledge pedigree. Even though CiteSpace has multiple functions of bibliometrics, it has major limitations for database selection. CiteSpace can perform a comprehensive bibliometric analysis of selected literature from the WoS database; but for other databases, some of its functions cannot be effectively implemented. For example, CiteSpace cannot realize the analysis of co-occurrence networks in countries or regions and the co-citation analysis of authors and literature when literature data is extracted from Derwent database and CNKI database. Therefore, in the future, if researchers want to perform bibliometric analysis on databases other than WoS, other visual bibliometric software, such as VOSviewer and social network analysis softwares are attemptable (e.g. [38, 53]. In addition, combining the merits of different bibliometrics tools together to perform the comprehensive research should be another concerned way for future comprehensive studies.

This article is an exploratory study and only chooses the key and classical functions of CiteSpace, so a comprehensive review could be enriched by more functions of CiteSpace in the future. For example, the time-line mapping can be used to verify the results of time zone map. Besides, the data can be updated regularly so as to further update the ET knowledge map provided by this study.

\section{Acknowledgements}

This work is supported by the National Natural Science Foundation of China (Grant No. 71471047).

\section{Conflict of Interest}

The authors declare no conflict of interest.

\section{References}

1. SELIGSOHN D., LIU M.D., ZHANG B. The sound of one hand clapping: transparency without accountability. Environ Polit, 27 (5), 804, 2018. DOI: 10.1080/09644016.2018.1452522

2. WONG C.W.Y., MIAO X., CUI S., TANG Y. Impact of corporate environmental responsibility on operating income: moderating role of regional disparities in China. J. Bus. Ethics., 149 (2), 363, 2018.

3. TIAN X.L., GUO Q.G., HAN C., AHMAD N. Different extent of environmental information disclosure across Chinese cities: contributing factors and correlation with local pollution. Glob. Environ. Change., 39, 244, 2016.

4. PENG M.G., ZHANG H., EVANS R.D. Actual Air Pollution, Environmental Transparency, and the Perception of Air Pollution in China. J Environ Dev, 28 (1), 78, 2019.

5. DINCA M.S., MADALENO M., BABA M.C. Environmental Information Transparency-Evidence from Romanian Companies. Sustainability, 11 (8), 5040, 2019.

6. SIMÕES P., MARQUES R. Influence of regulation on the productivity of waste utilities. What can we learn with the Portuguese experience? Waste Manage., 32 (6), 1266, 2012.

7. MASON M. Transparency, accountability and empowerment in sustainability governance: a conceptual review. J. Environ. Pol. Plan., 22 (1), 98, 2019.

8. CHEN S., ZHANG Q.Q., ZHOU Y.P. Impact of Supply Chain Transparency on Sustainability under NGO Scrutiny. Prod. Oper. Manag., 28 (12), 3002, 2019.

9. TARANTINO M. Navigating a dataspace: challenges in automating environmental data disclosure in China. Environ. Plan. Manag., 63 (1), 67, 2020.

10. SHI Y.L., LIU X.P. Research on the Literature of Green Building Based on the Web of Science: A Scientometric 
Analysis in CiteSpace (2002-2018). Sustainability, 11 (13), 3716, 2019.

11. DARKO A., CHAN A.P.C., HUO X.S., OWUSU-MANU D. A scientometric analysis and visualization of global environmental transparency research. Build. Environ., 149 (1), 501, 2019.

12. ZHANG W., ZHANG Q.P., YU B., ZHAO L.M. Knowledge map of creativity research based on keywords network and co-word analysis, 1992-2011. Qual. Quant., 49 (3), 1023, 2015

13. ZUO J., ZHAO Z.Y. Green building research-current status and future agenda: A review. Renew. Sustain. Energy Rev., 30, 271, 2014.

14. CHEN C.M. CiteSpace II: Detecting and visualizing emerging trends and transient patterns in scientific literature. J. Am. Soc. Inf. Sci. Tec., 57 (3), 359, 2006.

15. ZHANG Z. Visualization analysis of the development trajectory of knowledge sharing in virtual communities based on CiteSpace. Multimed. Tools. Appl., 78 (21), 229643, 2019.

16. ZHU J., HUA W.J. Visualizing the knowledge domain of sustainable development research between 1987 and 2015: A bibliometric analysis. Scientometrics, 110 (2), 893, 2017.

17. MOU J., CUI Y., KURCZ K. Bibliometric and Visualized Analysis of Research on Major E-Commerce Journals Using Citespace. J. Electron. Commer. Re., 20 (4), 219, 2019.

18. HE F., MIAO X., WONG C.W.Y., LEE Stacy. Contemporary corporate eco-innovation research: a systematic review. J. Clean. Prod., 174, 502, 2018.

19. ZHANG L., MOL A., HE G., LU Y. An implementation assessment of China's environmental information disclosure decree. J. Environ. Sci., 22 (10), 1649, 2010.

20. United Nations. Rio declaration on environment and development. Paper presented at the United Nations Conference on Environment \& Development, United Nations, Rio de Janerio, Brazil. 1992. Retrieved from https://sustainabledevelop- ment.un.org/content/ documents/Agenda21.pdf

21. United Nations Economic Commission for Europe. Convention on access to information, Public participation in decision-making and access to justice in environmental matters. Geneva, Switzerland: United Nations, 1998. Retrieved from https://www.unece. org/fileadmin/DAM/ env/pp/documents/cep43e.pdf

22. LI W., LI D. Environmental information transparency and implications for green growth in China. Public Admin Develop, 32 (3), 324, 2012.

23. SALEEM H.A. Questioning the Transparency Mantra in Green Governance. Int Stud Rev, 18 (2), 402, 2016.

24. CLARKSON P.M., LI Y., RICHARDSON G.D., VASVARI F.P. Does itreally pay to be green? Determinants and consequences of proactive environmental strategies. J. Account. Public. Pol., 30 (2), 122, 2011.

25. CHO C.H., PATTEN D.M. The role of environmental disclosures astools of legitimacy: A research note. Account. Org. Soc., 32 (7-8), 639, 2007.

26. GUTHRIE J.E., PARKER L.D. Corporate social disclosure practice: A comparative international analysis. Adv. Pub. Int., 3 (3), 159, 1990.

27. WILLIAMS S.M. Voluntary environmental and social accounting disclosure practices in the Asia-Pacific region: An international empirical test of political economy theory. The Int. J. Account. 34 (2), 209, 1999.

28. TIAN L.H., WANG K.D. The "disguise Effect" of Social Responsibility Information Disclosure and the Risk of
Collapse of Listed Companies - DID-PSM Analysis from Chinese Stock Market. Management World, 11 (1), 146157, 2017 [In Chinese].

29. BERNARDI C., STARK A.W. Environmental, social and governance disclosure, integrated reporting, and the accuracy of analyst forecasts. Br. Account. Rev., 50 (1), 16, 2018.

30. CHEN Y.S., CHANG C.H. Greenwash and green trust: the mediation effects of green consumer confusion and green perceived risk. J. Bus. Ethics., 114 (3), 489, 2013.

31. SIANO A., VOLLERO A., CONTE F., AMABILE S. "More than words": Expanding the taxonomy of greenwashing after the Volkswagen scandal. J. Bus. Res., 71, 27, 2017.

32. JI X.J., CHEN H.T., WANG D. Media Coverage, Government Supervision and Corporate Environmental Information Disclosure. Chinese Journal of Environmental Management, 11 (2), 44, 2019.

33. GUENTHER E., GUENTHER T., SCHIEMANN F., WEBER G. Stakeholder relevance for reporting: Explanatory factors of carbon disclosure. Bus. Soc., 55 (3), 361, 2016.

34. MOHER D., LIBERATI A., TETZLAFF J., ALTMAN D.G. Preferred reporting items for systematic reviews and meta-analyses: The PRISMA statement. Ann. Intern. Med., 151 (4), 1-8, 2009.

35. YAO Q., CHEN K., YAO L., LYU P.H., YANG T.A., LUO F., LIU Z.Y. Scientometric trends and knowledge maps of global health systems research. Health. Res. Policy. Sy., 12 (1), 2014.

36. ARCHAMBAULT E., CAMPBELL D., GINGRAS Y., \& LARIVIERE V. Comparing of Science Bibliometric Statistics Obtained from the Web and Scopus. J. Am. Soc. Inf. Sci. Tec., 60 (7), 1320, 2009.

37. HOU J.H., YANG X.C., CHEN C.M. Emerging trends and new developments in information science: A document cocitation analysis (2009-2016). Scientometrics, 115 (2), 869, 2018.

38. DE JONG M., SIMON J., DAAN S., ZHAN C.J., MARGOT W. Sustainable-smart-resilient-low carbon-ecoknowledge cities; making sense of a multitude of concepts promoting sustainable urbanization. J. Clean. Prod., 109, 25, 2015.

39. CABEZA R., LUIS J., SANCHEZ C.S., FUENTES G.F.J. Past Themes and Tracking Research Trends in Entrepreneurship: A Co-Word, Cites and Usage Count Analysis. Sustainability, 11 (11), 3121, 2019.

40. MEBANE C.A., SUMPTER J.P., FAIRBROTHER A., AUGSPURGER T.P., CANFIELD T.J., GOODFELLOW W.L., GUINEY P.D., LEHURAY A., MALTBY L., MAYFIELD D.B., MCLAUGHLIN M.J., ORTEGO L.S., SCHLEKAT T., SCROGGINS P., VERSLYCKE T.A. Scientific Integrity Issues in Environmental Toxicology and Chemistry: improving research reproducibility, credibility, and transparency. Integr. Environ. Assess. Manage., 15 (3), 320, 2019.

41. SMALL H., GRIFFITH B.C. The Structure of Scientific Literatures I: Identifying and Graphing Specialties. Sci. Stud., 4 (1), 17, 1974.

42. CAMBROSIO A., LIMOGES C., COURTIAL J.P., LAVILLE F. Historical scientometrics? Mapping over 70 years of biological safety research with coword analysis. Scientometrics, 27 (2), 119, 1993.

43. YING D., CHOWDHURY G.G., FOO S. Bibliometric cartography of information retrieval research by using coword analysis. Inform. Process. Manag., 37 (6), 817, 2001. 
44. ZONG Q., SHEN H., YUAN Q., HU X., HOU Z., DENG $S$. Doctoral dissertations of Library and Information Science in China: A co-word analysis. Scientometrics, 94 (2), 781, 2013.

45. CHEN C.M., HU Z.G., LIU S.B., TSENG H. Emerging trends in regenerative medicine: A scientometric analysis in CiteSpace. Expert Opin. Biol. Ther., 12 (5), 593, 2012.

46. CORRALES-GARAY D., ORTIZ-DE-URBINACRIADO M., \& MORA-VALENTIN E. Knowledge areas, themes and future research on open data: A co-word analysis. Gov. Inform. Q., 36 (1), 77, 2019.

47. SMALL H. Co-citation in the scientific literature: A new measure of the relationship between two documents. J. Am. Soc. Inf. Sci., 24 (4), 265, 1973.

48. MCCAIN K.W. Mapping authors in intellectual space: A technical overview. J. Am. Soc. Inf. Sci., 41 (6), 433, 1990.

49. ZHENG B.Y. The Clustering Analysis of Multivariable Panel Data and Its Application. Application of Statistics and Management, 27 (2), 265, 2008.

50. ZHANG Q., MA F.C. On paradigm of research knowledge management: A bibliometric analysis. Journal of Management Science in China, 10 (6), 65, 2007.

51. AN X.Y., WU Q.Q. Co-word analysis of the trends in stem cells field based on subject heading weighting. Scientometrics, 88 (1), 133, 2011.

52. SCHNEIDER J.W. Mapping scientific frontiers: The quest for knowledge visualization. J. Am. Soc. Inf. Sci. Technol., 55 (4), 363, 2004.

53. FENG Y.T., ZHU Q.H., KEE-HUNG L. Corporate Social Responsibility for Supply Chain Management: A Literature Review and Bibliometric Analysis. J. Clean. Prod., 158, 296, 2017.

54. KOTHARI A., HAMEL N., MACDONALD J., MEYER M., COHEN B., BONNENFANT D. Exploring Community Collaborations: Social Network Analysis as a Reflective Tool for Public Health. SPAR, 27 (2), 123, 2014.

55. GUPTA A. Transparency Under Scrutiny: Information Disclosure in Global Environmental governance. Glob. Environ. Polit., 8 (2), 1, 2008.

56. CLARKSON P.M., LI Y., RICHARDSON G.D., VASVARI F.P. Revisiting the relation between environmental performance and environmental disclosure: An empirical analysis. Account. Org. Soc., 33 (3-4), 303, 2008.

57. GUPTA A. Transparency in global environmental governance: a coming of age? Glob. Environ. Polit., 10 (3), 2010.

58. DHALIWAL D.S., LI O.Z., TSANG A., YANG Y.G. Voluntary Nonfinancial Disclosure and the Cost of Equity Capital: The Initiation of Corporate Social Responsibility Reporting. The accounting Review, 86 (1), 59, 2011.

59. BIERMANN F., GUPTA A. Accountability and legitimacy in earth system governance: A research framework. Ecol. Econ., 70 (11), 1856, 2011.

60. HAHN R., KUHNEN M. Determinants of sustainability reporting: a review of results, trends, theory, and opportunities in an expanding field of research. J. Clean. Prod., 59 (59), 5, 2013.

61. NAVARRO A., ALCARAZ F.J., ORTIZ D. The Disclosure of Corporate Social Responsibility Information in Public Administrations: An Empirical Study in Local Governments. Revista de Contabilidad, 13 (2), 285, 2010.

62. GARCIA-SANCHEZ I.M., FRIAS-ACEITUNO J.V., RODRIGUEZ-DOMINGUEZ, L. Determinants of corporate social disclosure in Spanish local governments. J. Clean. Prod., 39, 60, 2013.
63. DUNNING T. Accurate methods for the statistics of surprise and coincidence. Comput. Linguist., 19 (1), 61, 1993.

64. AGATHOKLEOUS E., ANAV A., ARAMINIENE V., MARCO A.D., DOMINGOS M., KITAO M., KOIKE T., MANNING W.J., PAOLETTI E., SAITANIS C.J., SICARD P., VITALE M., WANG W.J., CALABRESE E.J. Commentary: EPA's proposed expansion of doseresponse analysis is a positive step towards improving its ecological risk assessment. Environ. Pollut., 246, 566, 2019.

65. LUEG K., KRASTEV B., LUEG R. Bidirectional effects between organizational sustainability disclosure and risk. J. Clean. Prod., 229, 268, 2019.

66. KOSTKA G., ZHANG X.H., SHIN K. Information, technology, and digitalization in China's environmental governance. Environ. Plan. Manag., 63 (1), 1, 2019.

67. PACHE-DURAN M., NEVADO-GIL M.T. Disclosure of responsible information by Spain local government. Investig. Bibliotecol., 33 (81), 111, 2019.

68. VAN Q.L., NGUYEN T.V., NGUYEN M.H. Sustainable development and environmental policy: The engagement of stakeholders in green products in Vietnam. Bus. Strategy. Environ., 28 (5), 657, 2019.

69. CHENG Z.H., WANG F., KEUNG C., BAI Y.X. Will corporate political connection influence the environmental information disclosure level? Based on the panel data of a-shares from listed companies in shanghai stock market. J. Bus. Ethics., 143 (1), 209, 2017.

70. DU X.Q., JIAN W., ZENG Q., DU Y.J. Corporate environmental responsibility in polluting industries: Does religion matter? J. Bus. Ethics., 124 (3), 485, 2014.

71. WU J. Differentiated customer pressures and environmental policies in china. Bus. Strateg. Environ., 24 (3), 175, 2015.

72. ZHANG B., CAO C. Four gaps in china's new environmental law. Nature, 517 (7535), 433, 2015.

73. WANG R., WIJEN F., HEUGENS P.P.M.A.R. Government's green grip: Multifaceted state influence on corporate environmental actions in china. Strategic. Manage. J., 39 (2), 403, 2018.

74. MIAO X., TANG Y., \& WONG C.W.Y. Polluters migrate to China's poor areas. Nature, 518 (7540), 483, 2015.

75. HUNG LAU K. Benchmarking green logistics performance with a composite indicator. Benchmark. Int. J., 18 (6), 873, 2011.

76. HELFAYA A., KOTB A., HANAFI R. Qur'anic Ethics for Environmental Responsibility: Implications for Business Practice. J. Bus. Ethics., 150 (4), 1105, 2018.

77. Xinhua News Agency. Available online: http://news. xinhuanet.com/fortune/2015-10/29/c_1116983078.htm. (assessed on 12 May, 2020)

78. CHEN C.M. Searching for intellectual turning points: Progressive knowledge domain visualization. Proc. Natl. Acad. Sci. USA, 101 (1), 5303, 2004.

79. CHEN Y., MA Z.H., GU J.L., TIAN W.T. Environmental cost research: cooperation, evolution, hotspot and prospect. J. Arid. Environ., 33 (6), 11, 2019.

80. LI D.Y., XIN L.N., SUN Y., HUANG M., REN S.G. Assessing environmental information disclosures and the effects of Chinese nonferrous metal companies. Pol. J. Environ. Stud., 25 (2), 663, 2016.

81. HASSAN O.A.G., ROMILLY P. Relations between corporate economic performance, environmental disclosure and greenhouse gas emissions: New insights. Bus. Strateg. Environ., 27 (7), 893, 2018. 
82. PAN A.E., GUO Q.S. Government Regulation and the Disclosure of Enterprise Environmental Information Based on The Role of Environmental Protection Awareness of Executives. Soft Science, 32 (10), 84, 2018.

83. REID E.M., TOFFEL M.W. Responding to public and private politics: Corporate disclosure of climate change strategies. Strategic. Manage. J., 30 (11), 1157, 2009.

84. PAVLOPOULOS A., MAGNIS C., IATRIDIS, G.E. Integrated reporting: An accounting disclosure tool for high quality financial reporting. Res. Int. Bus. Financ., 49, 13, 2019.

85. BERNARDI C., STARK A.W. Environmental, social and governance disclosure, integrated reporting, and the accuracy of analyst forecasts Br. Account. Rev., 50 (1), 16, 2018.

86. BRANCO M.C., RODRIGUES L.L. Factors influencing social responsibility disclosure by Portuguese companies. J. Bus. Ethics., 83 (4), 685, 2018.

87. TANG Y., WU S., MIAO X., POLLARD S.J.T., HRUDEY S.E. Resilience to evolving drinking water contamination risks: a human error prevention perspective. J. Clean. Prod., 57, 228, 2013.

88. KIM S. The Process Model of Corporate Social Responsibility (CSR) Communication: CSR Communication and its Relationship with Consumers' CSR Knowledge, Trust, and Corporate Reputation Perception. J. Bus. Ethics., 154 (4), 1143, 2017. DOI: 10.1007/s10551-0173433-6

89. CHEN J., MENG S., ZHOU W. The exploration of fuzzy linguistic research: A scientometric review based on CiteSpace. J. Intell. Fuzzy Syst., 37 (3), 3655, 2019.
90. DELMAS M.A., \& BURBANO V.C. The drivers of greenwashing. Calif. Management Rev., 54 (1), 64, 2011.

91. TAN Y.L. Transparency without Democracy: The Unexpected Effects of China's Environmental Disclosure Policy. Governance, 27 (1), 37, 2014.

92. JACOBY G., LIU M.Z., WANG Y.F. Corporate governance, external control, and environmental information transparency: Evidence from emerging markets. J. Int. Financial Mark. Inst. Money, 58, 269, 2019.

93. ARENA C., BOZZOLAN S., MICHELON G. Environmental reporting: transparency to stakeholders or stakeholder manipulation? an analysis of disclosure tone and the role of the board of directors. Corp. Soc. Resp. Env. Ma., 22 (6), 346, 2015.

94. LURIA G., GAL I., YAGIL D. "Employees' willingness to report service complaints." J Serv Res-US, 12 (2), 156, 2009.

95. MIAO X., TANG Y., WONG C.W.Y., ZANG H.Y. The latent causal chain of industrial water pollution in china. Environ. Pollut., 196, 473, 2015.

96. YIN R. Case study research design and methods (Fourth.). London: SAGE Publications Ltd. 2009.

97. MEYER C.B. A case in case study methodology. Field methods, 13 (4), 329, 2011.

98. SHOJAEI P., HAERI S.A.S. Development of supply chain risk management approaches for construction projects: A grounded theory approach. Comput. Ind. Eng., 128, 837, 2019. 